\title{
O sentimento que nos faz irmãs: construções discursivas da sororidade em mídias sociais
}

The feeling that makes us sisters:

discursive constructions of sisterhood in social media

El sentimiento que nos hace hermanas:

construcciones discursivas de la sororidad en las redes sociales

\section{Tatiane Leal}

Pesquisadora de Pós-Doutorado do Instituto Nacional de Comunicação Pública da Ciência e Tecnologia (INCT-CPCT), vinculado à Fundação Oswaldo Cruz (Fiocruz), com bolsa Faperj. Doutora e Mestre em Comunicação e Cultura pela Universidade Federal do Rio de Janeiro (UFRJ). Vice-líder do Núcleo de Estudos de Mídia, Emoções e Sociabilidade (NEMES).

\section{RESUMO}

A palavra sororidade, uma espécie de sentimento de irmandade entre mulheres, sequer chegou aos dicionários, mas já motiva uma série de textos ativistas, jornalísticos $e$ publicitários dispersos na internet. Neste artigo, faço uma análise do discurso foucaultiana das definições de sororidade presentes nos links mais compartilhados sobre o tema em sites de redes sociais. Dois eixos são explorados: a associação do conceito ao campo semântico dos sentimentos, especialmente à empatia; e as diferentes origens atribuídas à sororidade, vista ora como parte de uma essência feminina, ora como resultado de uma postura ético-política desenvolvida a partir da sociabilidade entre mulheres. A investigação do conceito revela, a partir de uma perspectiva de gênero, o nexo entre sentimentos, moralidade e política em processos comunicacionais contemporâneos.

PALAVRAS-CHAVE: Sororidade. Feminismo. Sentimentos Morais. Internet.

Dossiê Crise, Feminismo e Comunicação - https://revistaecopos.eco.ufrj.br/

ISSN 2175-8689 - v. 23, n. 3, 2020

DOI: 10.29146/eco-pos.v23i3.27601 


\section{ABSTRACT}

The word sororidade means a feeling of sisterhood in Portuguese, but has not yet been included in Brazilian dictionaries. It has motivated a series of activist, journalistic and publicity texts scattered through the internet. In this paper, I make a Foucauldian discourse analysis of the most-shared links on the subject on social networking websites, collected with the BuzzSumo monitoring tool, with a focus on those dedicated to elaborating definitions of sisterhood. There are two lines of exploration: the association of the concept with the semantic field of feelings, especially empathy; and the different origins attributed to sisterhood, seen either as part of an essence of womanhood or as a result of an ethical-political stance developed out of sociability among women. The investigation of the concept from the perspective of gender reveals the nexus between feelings, morality, politics in contemporary communicational processes.

KEYWORDS: Sisterhood. Feminism. Moral Sentiments. Internet.

\section{RESUMEN}

La palabra sororidad, una especie de sentimiento de hermandad entre mujeres, ni siquiera ha llegado a los diccionarios, pero ya motiva una serie de textos activistas, periodísticos y publicitarios dispersos en internet. En este artículo, hago un análisis del discurso de Foucault sobre las definiciones de sororidad presentes en los links más compartidos sobre el tema en los sitios de redes sociales. Se exploran dos caminos: la asociación del concepto con el campo semántico de los sentimientos, especialmente la empatía; y los diferentes orígenes atribuidos a la sororidad, vista a veces como parte de una esencia femenina, a veces como resultado de una postura ético-política desarrollada a partir de la sociabilidad entre las mujeres. La investigación del concepto revela, desde una perspectiva de género, el nexo entre sentimientos, moral y política en los procesos de comunicación contemporáneos. PALABRAS CLAVE: Sororidad. Feminismo. Sentimientos morales. Internet.

\section{Introdução}

Do latim soror (irmã), a palavra sororidade - ou uma espécie de sentimento de irmandade entre mulheres - sequer chegou aos dicionários de Língua Portuguesa, mas encontrou na mídia contemporânea um espaço fértil para circulação. Esse processo, articulado a uma efervescência de discursos feministas, intensifica-se no ambiente on-line. Em 2017, “o que é sororidade?” foi a quinta pergunta mais feita ao Google por usuários brasileiros na categoria "o que é"1. Em

${ }^{1}$ https://trends.google.com.br/trends/yis/2017/BR/. Acesso: 28 ago. 2020.

Dossiê Crise, Feminismo e Comunicação - https://revistaecopos.eco.ufrj.br/

ISSN $2175-8689$ - v. 23, n. 3, 2020

DOI: 10.29146/eco-pos.v23i3.27601 
2020, a busca pelo termo na ferramenta disparou mais de $250 \%$, após a cantora Manu Gavassi ter mencionado a sororidade em uma edição ao vivo do reality show Big Brother Brasil (BBB20), da Rede Globo². O volume do interesse em seu significado parece indicar uma circulação do vocábulo para além dos espaços de militância.

Em dicionários on-line já é possível encontrar algumas tentativas de delimitar os sentidos do termo. Nessas definições, a sororidade é associada ao movimento feminista, combinando um vocabulário de teor político e emocional, com menções a sentimentos como "amizade", "afeição" e "afeto":

Sororidade é o pacto entre as mulheres que são reconhecidas irmãs, sendo uma dimensão ética, política e prática do feminismo contemporâneo (Dicionário Informal). ${ }^{3}$

Relação de irmandade, união, afeto ou amizade entre mulheres, assemelhando-se àquela estabelecida entre irmãs. União de mulheres que compartilham os mesmos ideias e propósitos, normalmente de teor feminista (Dicionário Online de Português). ${ }^{4}$

As repostas à pergunta "o que é sororidade?" chegam a mais de 880 mil resultados no Google ${ }^{5}$, com páginas que transitam entre os mais variados formatos: textos jornalísticos, manifestos políticos de blogs, manuais pedagógicos, anúncios publicitários e resenhas de produtos midiáticos. Esses discursos, entre similaridades e discordâncias, apresentam definições, promovem defesas, criticam limites e associam a diferentes práticas o conceito de sororidade.

Nesses enunciados, a sororidade é apresentada frequentemente como uma ferramenta capaz de mobilizar ações políticas, retirando as mulheres do isolamento e possibilitando a união de sua força em prol de objetivos feministas. Delineia-se, em discursos como esse, uma relação entre o conceito e questões morais - a sororidade

\footnotetext{
${ }^{2}$ https://www.huffpostbrasil.com/entry/sororidade-manugavassi br 5e442423c5b61b84d3438b88. Acesso: 28 ago. 2020.

3 http://www.dicionarioinformal.com.br/relacionadas/sororidade/. Acesso: 28 ago. 2020.

${ }^{4}$ https://www.dicio.com.br/sororidade/. Acesso: 28 ago. 2020.

5 Dados referentes à busca das palavras chave o que é sororidade no Google em 28 ago. 2020. https://www.google.com.br/
}

Dossiê Crise, Feminismo e Comunicação - https://revistaecopos.eco.ufrj.br/

ISSN 2175-8689 - v. 23, n. 3, 2020

DOI: 10.29146/eco-pos.v23i3.27601 
teria o potencial de mostrar às mulheres a maneira correta de agir, possibilitando transformações na sociedade. Portanto, palavras já existentes, como empatia, amizade e solidariedade, passam a não dar conta de expressar o que diversas ativistas feministas contemporâneas declaram sentir em relação a outras mulheres. É preciso dar um nome específico a esse tipo de sentimento para que ele tenha uma potência política.

Seria possível, então, afirmar que a sororidade é um chamado ético que interpela o movimento feminista contemporâneo, com base em um sentimento - ou um conjunto deles - partilhado por uma irmandade imaginada de mulheres? 0 uso do termo sentimento aqui não é casual. Os discursos sobre a sororidade indicam que a base ética desses feminismos proliferados na mídia está no terreno das emoções. Para a reportagem "Sororidade: substantivo feminino", publicada no jornal $O$ Globo em 2016, “(...) o sentimento expresso pelo termo é um instrumento para a conquista da igualdade entre mulheres e homens" (grifo meu) ${ }^{6}$.

Pensando os sentimentos em uma perspectiva histórica e política, Irvine (2007) propõe o conceito de sentimentos transitórios (transient feelings) para pensar determinadas palavras que aparecem, em um determinado momento, com grande proeminência em discursos de uma sociedade, organizando um fluxo de sentimentos e valores em torno de si. Com eles, seria possível mapear características específicas de determinado momento histórico, como agentes, práticas, instituições, estratégias discursivas, representações midiáticas e movimentos políticos.

Essa cartografia permitiria compreender a erupção de sentimentos em determinada sociedade, bem como os processos pelos quais os indivíduos os incorporam ou rejeitam. A ideia de sentimento transitório permite pensar as conexões cruciais entre movimentos sociais, mídia, Estado e indivíduos como condições de possibilidade para a emergência de novos entendimentos acerca das emoções e de seus vínculos com a sociabilidade, a moral e a política. Ainda que

6 https://oglobo.globo.com/mundo/sororidade-substantivo-feminino-18959230. Acesso: 28 ago. 2020 .

Dossiê Crise, Feminismo e Comunicação - https://revistaecopos.eco.ufrj.br/

ISSN 2175-8689 - v. 23, n. 3, 2020

DOI: 10.29146/eco-pos.v23i3.27601 
elaborações sobre a irmandade feminina e sentimentos de solidariedade entre mulheres perpassem a história do feminismo (Costa, 2009), a reivindicação do termo sororidade no Brasil atual reverbera processos específicos. Assim, podemos compreender a sororidade como um sentimento que responde a um conjunto de necessidades do contemporâneo, engendrando uma série de práticas que participam da construção das realidades que se articulam ao conceito como uma experiência vivida.

Este artigo se situa em uma pesquisa mais ampla na qual realizo uma análise de discursos midiáticos contemporâneos sobre a sororidade, a partir uma reflexão sobre sentimentos e moralidade, pensando o conceito de sororidade articulado a éticas feministas contemporâneas, em um diálogo com a filosofia moral britânica do século XVIII e a noção de sentimento moral (Leal, 2019). Reconheço, assim a posição central da mídia como mediadora sociocultural na construção de moralidades, subjetividades e formas de ação política no contemporâneo.

A necessidade de realizar pesquisas sobre feminismo na Comunicação se justifica, dentre outros motivos, pela efervescência que o movimento atravessa na contemporaneidade. Essa prática política e pensamento filosófico, que defende a equidade de direitos entre os gêneros, atravessa o que Ahmed (2017) define como momentum, ou um período em que é possível testemunhar uma adesão global em massa ao seu projeto, com mais pessoas dispostas a protestar, nas ruas e nas redes, por suas causas.

Apesar de a relação entre feminismo e mídia não ser uma novidade, já que, historicamente, o movimento utilizou meios de comunicação como a imprensa para difundir suas ideias (Buitoni, 1986; Duarte, 2016), compreender esse momentum é, necessariamente, considerar o papel da mídia e discutir suas mediações socioculturais. Nas formulações de ativistas, o que distingue o movimento hoje de outros momentos históricos é o caráter massivo que ele adquire a partir da viralização de seus discursos nos espaços da internet. Com isso, o feminismo contemporâneo seria um movimento, ao mesmo tempo, político e midiático (Queiroz, 2016).

\section{Dossiê Crise, Feminismo e Comunicação - https://revistaecopos.eco.ufrj.br/}

ISSN 2175-8689 - v. 23, n. 3, 2020

DOI: 10.29146/eco-pos.v23i3.27601 
Por esse motivo, este artigo se concentra na análise de discursos sobre as definições de sororidade compartilhados em sites de redes sociais. 0 que esses enunciados afirmam? Que práticas sociais produzem? Quais são os aspectos do contemporâneo que fornecem as condições de possibilidade para que a sororidade seja considerada uma categoria política relevante? Investigo essas narrativas a partir de uma perspectiva foucaultiana. Para o filósofo francês, o enunciado é um acontecimento, à medida que ele irrompe em determinado espaço-tempo. Nem todo enunciado poderia ter sido formulado em qualquer lugar ou tempo, não por ser proibido, mas por não ser pensável. A questão que se coloca é “(...) como apareceu um determinado enunciado, e não outro em seu lugar?" (Foucault, 2009).

Analisar discursos a partir de Foucault é, assim, investigar as condições de emergência, que permitiram o aparecimento de determinado enunciado. Foucault refuta ainda a ideia de que a vida social e o sujeito sejam pré-existentes ao discurso, a que caberia a função de retratá-los. 0 discurso é, ao contrário, uma prática que constrói essa realidade à medida que a nomeia. Assim, afirmar que há uma invenção da sororidade no contemporâneo não significa considerá-la como algo falso ou imaginário, mas compreender que esse conceito ganha uma série de possibilidades de existência a partir da sua enunciação, e que a ordem de discursos sobre ela engendra uma série de práticas e oferece aos sujeitos a possibilidade de ocupar determinadas posições. Isso significa que não há uma sororidade pura, real, que é (mal ou bem) representada pelos textos midiáticos, mas que ela é produzida pelos discursos que a nomeiam. É nesse sentido que investigo não o que os textos retratam, mas o que elaboram a partir de suas concepções e apropriações da sororidade em termos de sentidos e de práticas.

Em um contexto contemporâneo em que a efervescência do feminismo convive com a ascenção de discursos conservadores sobre gênero e sexualidade (Anjos, 2019), interessa-me compreender as práticas e subjetividades engendradas pelas definições de sororidade que circulam nas mídias sociais. Embates discursivos entre os múltiplos feminismos, já que a ideia de um movimento no singular não se sustenta no contemporâneo (Hollanda, 2019), também motivam a investigação desse conceito que propõe uma irmandade entre mulheres, de forma a descobrir 
que possíveis sociabilidades femininas em convergência e disputa se constroem nesses discursos.

\section{Percurso metodológico}

Neste artigo, combinei métodos quantitativos e qualitativos para fazer uma análise exploratória de discursos sobre a sororidade dispersos no ambiente on-line. Para definir o corpus, foi utilizado o BuzzSumo ${ }^{7}$, uma ferramenta de monitoramento de sites de redes sociais, para coletar os 100 links mais compartilhados com a palavra-chave "sororidade" no Facebook, Linkedin, Twitter e Pinterest durante dois anos (1ํ fev. 2016 e 31 jan. 2018). Para a pesquisa, foi utilizada a versão gratuita de testes da ferramenta. 0 período de 2016 a 2018 comporta os anos que se seguem a chamada Primavera Feminista, em 2015, em que uma série de manifestações ligadas ao movimento proliferou no Brasil, movimentando ruas e redes em torno de pautas feministas (Bogado, 2019). Utilizei filtros para encontrar resultados referentes a sites brasileiros e conteúdos de língua portuguesa. Foram descartados 13 links quebrados e repetidos. Portanto, a amostra válida consistiu em 87 links.

Utilizei a análise do discurso (AD) de inspiração foucaultiana para tratar os resultados encontrados. A partir dos passos metodológicos da $\mathrm{AD}$ apresentados por Gill (2002), os links foram acessados, lidos e examinados considerando todo o seu conteúdo multimídia. Tendo como perspectiva a concepção de discurso de Foucault, o objetivo foi analisar qualitativamente que subjetividades e práticas são engendradas a partir das definições de sororidade que esses textos trazem, compreendendo a sua emergência como um acontecimento histórico que dialoga com o contexto sociocultural em que são produzidos e compartilhados ${ }^{8}$. A partir dessa investigação prévia, criei quatro categorias para agrupar os discursos a partir das temáticas e dos objetivos que apareceram na amostra.

Os textos agrupados sob a categoria definições de sororidade $(16,7 \%)$ apresentam o significado do conceito, demarcando quais seriam suas

\footnotetext{
${ }^{7}$ http://buzzsumo.com/. Acesso: 28 ago. 2020.

8 Para uma discussão mais ampla da análise do discurso foucaultiana, ver Leal (2019).
} 
potencialidades. Já a categoria sororidade na prática $(39,3 \%)$ abarca discursos centrados em histórias reais em que esse sentimento impulsionou iniciativas, projetos e campanhas. Em sororidade na mídia (34,5\%), os textos analisam a presença ou ausência da mesma em produtos comunicacionais como séries, filmes, celebridades ou campanhas de marketing. Por fim, em limites da sororidade $(9,5 \%)$ encontramos os discursos que criticam o conceito, apontando problemas e deficiências em suas utilizações. No gráfico 1, pode-se ver a distribuição dos textos entre as categorias de análise:

Gráfico 1: Porcentagem da ocorrência das categorias de análise definidas a partir dos conteúdos mais compartilhados sobre a sororidade

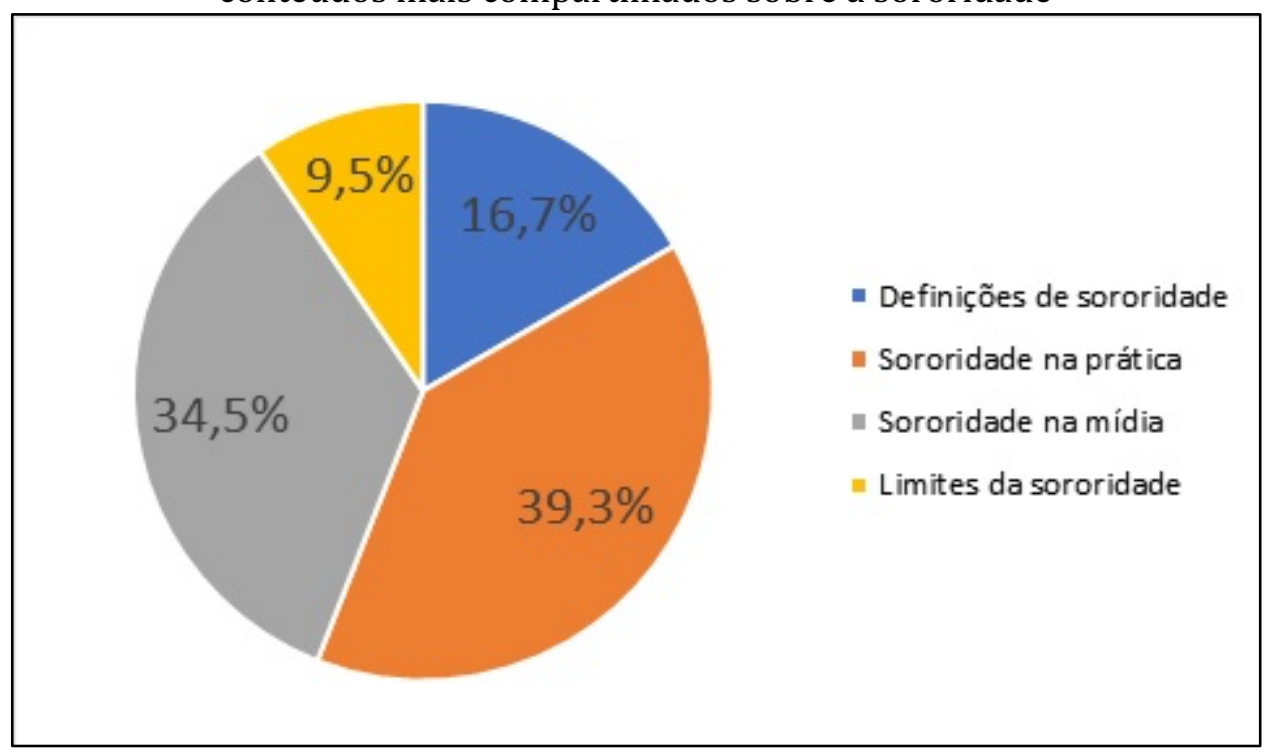

Fonte: A autora (2020).

Foram observados também em que veículos os textos foram publicados: blogs feministas, revistas femininas, jornais e sites de conteúdo específico, como cultura e direito, apareceram entre os resultados. É importante ressaltar que não busco aqui comparar diretamente objetos tão distintos em seus modos de produção, seus formatos e seus públicos-alvo, mas investigar, em suas continuidades e descontinuidades, as práticas políticas e subjetivas que se delineiam em torno do conceito de sororidade. 
Após essa análise exploratória, discuto, nesse artigo, os catorze textos agrupados sob a categoria definições de sororidade. Apesar de sororidade na prática ter sido a categoria mais numerosa, revelando que a exibição de histórias reais mobilizadas pelo sentimento foi a estratégia enunciativa predominante entre os textos mais compartilhados em sites de redes sociais, interessa-me, em um primeiro momento, examinar os discursos que buscaram delimitar definições básicas do conceito. Os textos que compõem a amostra analisada nesse artigo são apresentados na Tabela 1.

Tabela 1: Discursos da categoria definições de sororidade e seus respectivos veículos de publicação, em ordem decrescente de número de compartilhamentos

\begin{tabular}{|c|c|c|}
\hline Titulo & Veículo & Descrição do veículo \\
\hline $\begin{array}{l}\text { Sororidade é a palavra que traz a lição mais } \\
\text { importante do feminismo }\end{array}$ & HuffPost Brasil & Portal agregador de blogs \\
\hline Sororidade & O Mundo de Gaya & Site de esoterismo \\
\hline $\begin{array}{l}\text { O que é sororidade e por que precisamos } \\
\text { falar sobre? }\end{array}$ & Justificando & $\begin{array}{l}\text { Portal sobre direito vinculado à revista } \\
\text { Carta Capital }\end{array}$ \\
\hline Sororidade, substantivo feminino & O Globo & Site de jornal do Rio de Janeiro \\
\hline $\begin{array}{l}\text { O que quer dizer "sororidade" e por que } \\
\text { você precisa dela }\end{array}$ & Claudia & Site de revista feminina \\
\hline Significado de sororidade & Significados & Dicionário on-line \\
\hline $\begin{array}{l}\text { "O que é sororidade?" foi uma das perguntas } \\
\text { mais feitas no Google }\end{array}$ & $\begin{array}{l}\text { Cosmopolitan } \\
\text { (texto 1) }\end{array}$ & Site de revista feminina \\
\hline $\begin{array}{l}\text { Mônica Martelli: precisamos falar sobre } \\
\text { sororidade }\end{array}$ & $\begin{array}{l}\text { Cosmopolitan } \\
\text { (texto 2) }\end{array}$ & Site de revista feminina \\
\hline $\begin{array}{l}\text { Dicionários devem inserir palavras como } \\
\text { "sororidade" e "feminicidio" }\end{array}$ & $\begin{array}{c}\text { Correio } \\
\text { Braziliense }\end{array}$ & Site de jornal de Brasilia \\
\hline $\begin{array}{l}\text { Sororidade: as meninas do indiretas do Bem } \\
\text { explicam por que não devemos ser rivais }\end{array}$ & Capricho & $\begin{array}{l}\text { Site de revista feminina para o público } \\
\text { adolescente }\end{array}$ \\
\hline Sororidade & Projeto estelar & $\begin{array}{l}\text { Canal no Youtube para intercâmbio de } \\
\text { conhecimentos femininos }\end{array}$ \\
\hline $\begin{array}{c}\text { Empatia, lugar de falar e sororidade: elas } \\
\text { não desistiram }\end{array}$ & Blogueiras Negras & $\begin{array}{c}\text { Blog coletivo sobre e para mulheres } \\
\text { negras }\end{array}$ \\
\hline Um perfume para a sororidade & Vertigem & $\begin{array}{l}\text { Revista on-line de cultura e } \\
\text { comportamento feita por mulheres }\end{array}$ \\
\hline $\begin{array}{l}\text { Sobre sororidade, liberdade e interpretação } \\
\text { de texto }\end{array}$ & $\begin{array}{l}\text { Temos que falar } \\
\text { sobre isso }\end{array}$ & $\begin{array}{l}\text { Blog de organização não } \\
\text { governamental (ONG) e plataforma de } \\
\text { relatos anônimos para mulheres, } \\
\text { especialmente sobre maternidade }\end{array}$ \\
\hline
\end{tabular}


Fonte: A autora (2020), com dados do BuzzSumo.

A discussão se estrutura em dois eixos. No primeiro, discorro sobre a relação entre a sororidade e outros sentimentos, especialmente a empatia, e à ideia de irmandade feminina em contextos históricos do feminismo. No segundo, apresento algumas descontinuidades encontradas entre os textos: enquanto alguns consideram a sororidade como parte de uma essência feminina, distanciando-se da formação discursiva do feminismo, outros defendem que o sentimento somente emerge a partir da prática, constituindo um instrumento político.

\section{Sentimentos morais: uma genealogia da sororidade}

Uma definição que se repete constantemente nos textos analisados é a de que a sororidade seria uma aliança entre mulheres, baseada em uma série de conceitos que pertencem ao campo semântico sentimental. Constituindo, em si mesma, um sentimento, a sororidade seria capaz de superar outros como o ódio, a inveja e o ciúme e mobilizar ainda a amizade, a solidariedade e a indignação frente ao patriarcado. Mas, o sentimento que aparece mais fortemente associado à ideia de sororidade é a empatia. Essa relação apareceu em nove dos catorze textos analisados. Para a matéria "Sororidade: substantivo feminino", de $O$ Globo, o termo seria utilizado para "expressar empatia entre mulheres":

Um substantivo feminino ausente de dicionários clássicos de língua portuguesa vem sendo repetido com vigor entre jovens mulheres que militam pela igualdade de gênero. Disseminada em redes sociais, a palavra é salpicada em frases como "A sororidade pode salvar vidas", "Sororidade gera sororidade" ou, ainda, "Estamos aqui umas pelas outras. Isso é sororidade". Numa definição corrente na internet, "sororidade" se refere a uma espécie de pacto entre mulheres relacionado às dimensões ética, política e prática do feminismo contemporâneo. $\mathrm{Ou}$, simplesmente, uma aliança baseada na empatia e no companheirismo. ${ }^{9}$

9 https://oglobo.globo.com/mundo/sororidade-substantivo-feminino-18959230. Acesso: 28 ago. 2020.

Dossiê Crise, Feminismo e Comunicação - https://revistaecopos.eco.ufrj.br/

ISSN 2175-8689 - v. 23, n. 3, 2020

DOI: 10.29146/eco-pos.v23i3.27601 
Nos discursos de Cosmopolitan (texto 1) ${ }^{10}$, de Temos que falar sobre isso e de Capricho a sororidade é definida ainda como um movimento empático de colocar-se no lugar da outra, tanto para compreender seu modo de agir quanto para compartilhar de seus sentimentos. Esse apelo de colocar-se no lugar do outro, que mobiliza essas reflexões contemporâneas, motivou historicamente uma série de debates, em campos como a filosofia e a psicologia, sobre os conceitos de simpatia e empatia. Haveria uma faculdade humana que faria com que fôssemos capazes de acessar pensamentos, sentimentos e desejos do outro? O potencial de sentir as emoções do outro seria capaz de promover ações eticamente orientadas? No vídeo de Capricho, além de diversas menções à empatia, há ainda a afirmação: "a sororidade é você ter simpatia pela outra menina"11.

Esses conceitos transitam em torno do mesmo campo semântico que a sororidade: são, por vezes, considerados sentimentos em si mesmos, ou, em outras ocasiões, vistos como dimensões da experiência humana capazes de despertar e promover o compartilhamento de outras paixões. A ideia de que a sororidade seria uma empatia no feminino entende esse sentimento como um desdobramento específico da empatia, definida no dicionário Houaiss (2009) como "capacidade de se identificar com outra pessoa, de sentir o que ela sente, de querer o que ela quer, de apreender do modo como ela apreende etc".

Os achados empíricos confirmam que para fazer uma investigação genealógica da sororidade é necessário traçar o percurso histórico dos conceitos de simpatia e de empatia, compreendendo o contexto em que eles emergiram e as continuidades e descontinuidades entre seus significados contemporâneos. No século XVIII, opondo-se às teorias da moralidade extrínseca, que consideravam que as leis que orientavam a ação humana vinham de fora (de Deus ou do Estado), filósofos vinculados ao empirismo escocês propuseram uma internalização das fontes morais: é pelo sentimento experimentado diante das possibilidades de ação

10 https://cosmopolitan.abril.com.br/estilo-de-vida/o-que-e-sororidade-foi-uma-das-perguntasmais-feitas-no-google/. Acesso: 28 ago. 2020.

11 https://capricho.abril.com.br/vida-real/sororidade-as-meninas-do-indiretas-do-bem-explicampor-que-nao-devemos-ser-rivais/. Acesso: 28 ago. 2020.

Dossiê Crise, Feminismo e Comunicação - https://revistaecopos.eco.ufrj.br/

ISSN 2175-8689 - v. 23, n. 3, 2020

DOI: 10.29146/eco-pos.v23i3.27601 
que o homem poderia compreender o que é virtuoso e reprovável. Assim, toda ação moral deveria ser mediada através das afecções, fundando uma ética articulada com a vida sensorial (Taylor, 2013).

Nesse contexto, a simpatia representava, no pensamento de Hume (2009) e Smith (2015a), uma bússola moral capaz de guiar as ações virtuosas e afastar as viciosas, constituindo uma base ética para o estabelecimento de vínculos entre os indivíduos e promovendo a coesão social em um contexto de ascensão do capitalismo. Não havia uma pretensão universal em torno da simpatia: ela seria mais facilmente despertada por aqueles capazes de motivar admiração, principalmente, a partir de suas posses materiais, de sua posição de poder e de sua proximidade e semelhança com o observador.

O que foi definido, no contexto do século XVIII, como simpatia seria melhor entendido hoje a partir de outra palavra, que entra em uso apenas no início do século XX: a empatia. Tornada uma buzzword no mundo contemporâneo, ela é apresentada como mote de campanhas humanitárias e de movimentos sociais (Grey, 2011; Smith, 2015b). 0 conceito emerge, inicialmente, no campo da estética, mas é na psicologia que seu espraiamento é significativo. A empatia, nesse sentido, referia-se a uma capacidade de sentir o que o outro está sentido. Diferentemente da simpatia na filosofia moral do século XVIII, essa acepção psicológica trazia uma pretensão universal: não seria necessário um alinhamento moral ou uma proximidade com a alteridade para experimentá-la: a empatia seria um solvente universal, capaz de conectar quaisquer indivíduos nas mais variadas situações (Coplan e Goldie, 2011; Debes, 2015; Smith, 2015b). Enquanto a simpatia dependia de uma projeção imaginativa que diminuía o grau das paixões vivenciadas pelo observador (algo como eu sinto dor pela sua dor), a empatia seria a incorporação direta dessas emoções (eu sinto sua dor) (Frevert, 2011).

Uma diferença fundamental entre a simpatia e a empatia é que a primeira requer uma consideração positiva sobre o outro (Smith, 2015a). Já a empatia prescinde desse alinhamento moral: não só é possível, como desejável ter empatia com o outro distante, com aquele que se odeia ou que tem uma conduta reprovável. A empatia é vista como uma ponte capaz de transportar os sujeitos para um mundo 
que não lhes pertence. A partir desse entendimento, ela se torna uma panaceia para a solução de problemas em uma sociedade cada vez mais atomizada (Smith, 2015b). No entanto, a necessidade de não apagar diferenças de posicionamento entre eu e outro no contexto da empatia vem sendo extensamente explorada pelo feminismo hoje, a partir do conceito de lugar de fala e da perspectiva da interseccionalidade entre identidades como as de gênero, raça e classe e da demanda pelo reconhecimento da diferença entre a experiência das mulheres a partir dessas intersecções (Ribeiro, 2017).

Para relacionar a sororidade a essa discussão, é necessário refletir brevemente sobre algumas construções acerca da ideia de irmandade feminina na história do feminismo. As palavras sister e sisterhood já eram empregadas em discursos da primeira onda feminista norte-americana, como no caso da expressão "nossas irmãs nativas americanas" utilizada em um jornal do século XIX da Associação Nacional de Mulheres Americanas pelo Sufrágio, em que se nota uma tentativa de unir mulheres de diferentes contextos sob o escopo da sisterhood. Posteriormente, a noção de irmandade foi fundamental para a segunda onda na década de 1960, com o slogan Sisterhood is powerful! e os grupos de conscientização, espaços em que mulheres se reuniam para compartilhar vivências de opressão e debater ideais feministas. Pertencer a uma sisterhood significava ir além da amizade para trabalhar por outras mulheres em um sentido político, e era nesse ponto que residia grande parte da força que o movimento adquiriu nesse contexto (Zayton e Ezekiel, 2016).

Na França, o slogan Sisterhood is powerful! foi usado sem tradução no primeiro periódico da segunda onda do movimento francês, Le Torchon Brûle (197173) (Zaytoun e Ezekiel, 2016). No entanto, Fraisse (2012), ressalta que, apesar da popularização do slogan norte-americano nas manifestações de rua, o termo sororité não surge como mera tradução do inglês, mas emerge na linguagem feminista local. Tanto o conceito de sisterhood quanto o de sororité motivaram uma série de revisões e críticas durante a terceira onda feminista, especialmente por usos e práticas que homogeneizavam as experiências femininas e invisibilizavam as relações de poder

Dossiê Crise, Feminismo e Comunicação - https://revistaecopos.eco.ufrj.br/

ISSN $2175-8689$ - v. 23, n. 3, 2020

DOI: 10.29146/eco-pos.v23i3.27601 
entre mulheres, bem como a invisibilidade das experiências políticas de mulheres negras e de países periféricos nas narrativas históricas do feminismo (Costa, 2009).

Segundo Costa (2009), o único registro do termo sororidade no Brasil no campo acadêmico ocorre em um artigo de Lia Machado do início da década de 1990 sobre a coletânea francesa D'amour et de raison, organizada por Françoise Collin a partir de um seminário para a crítica da ideia e da prática da sororité em 15 anos de grupos feministas desse país (1968-1983). Apesar disso, a ideia de um laço sororal entre mulheres se materializava em práticas nos anos 1970-80 no Brasil, como os grupos de consciência. Destacava-se o compartilhamento de experiências centradas em eventos biológicos e vivências sociais que seriam comuns para a maioria das mulheres (Costa, 2009). Entretanto, a cisão de grupos de mulheres negras e lésbicas e, posteriormente, a crítica acadêmica de que essa irmandade comum não foi capaz de assegurar direitos iguais para todas as mulheres antecipavam críticas realizadas no contemporâneo nos debates sobre sororidade e a empatia.

As diversas definições da sororidade encontradas nas mídias sociais apresentam continuidades e descontinuidades desse conceito em relação à simpatia e à empatia, bem como às diferentes noções de irmandade na história do feminismo. Nos textos agrupados sob a categoria, há em comum a crença de que a sororidade, assim como a empatia, consegue transpor essas fronteiras identitárias e promover uma irmandade feminina, mas eles apresentam algumas divergências importantes referentes a esse debate sobre identidade e diferença. Em alguns dos discursos, a união através das diferenças aparece como um desdobramento óbvio da empatia, como no vídeo publicado pelo canal Projeto Estelar, uma "plataforma de empoderamento feminino" criada por Paola de Orleans e Bragança, integrante da família imperial brasileira, que traz a seguinte definição para a sororidade:

É querer o bem da outra, não importa a classe social, não importa a cor, não importa o que ela veste, daonde (sic) ela vem, não importa. (...) sororidade é uma rede viva de apoio mútuo. 0 que importa é

Dossiê Crise, Feminismo e Comunicação - https://revistaecopos.eco.ufrj.br/

ISSN 2175-8689 - v. 23, n. 3, 2020

DOI: 10.29146/eco-pos.v23i3.27601 
entender que nós mulheres dividimos uma unidade, claro que respeitando a essência individual de cada uma. ${ }^{12}$

Aqui, as assimetrias de raça e classe entre mulheres são rapidamente dispensadas, como questões que podem ser facilmente resolvidas - elas "não importam", o que deve ser observado é a "essência individual" de cada mulher. A própria posição social da apresentadora do vídeo, pertencente a um grupo da elite brasileira, poderia ser problematizada enquanto porta-voz dessa definição.

No vídeo, a sororidade é definida como “(...) ser quem eu quiser sem ser julgada, fazer o que eu quiser sem ser julgada, falar o que eu quiser sem ser julgada. Tipo 'miga sua louca, você pode fazer o que você acredita que eu vou tá do seu lado!'” . Há o reforço de uma ética contemporânea que tenha único como balizamento o indivíduo (Taylor, 2011). A visão do conceito aqui aproxima-se mais de uma sensibilidade pós-feminista, momento em que o feminismo se aproximaria de uma retórica neoliberal ao privilegiar a liberdade de escolha e o empoderamento individual, sem necessariamente desafiar as estruturas sociais (Gill, 2007; McRobbie, 2006). Assim, o entendimento da diferença sai de um foco mais coletivo e social para uma visão neoliberal: a ideia de que cada sujeito seria único e teria direito às próprias escolhas, enfraquecendo o potencial político da sororidade. Como aparece no discurso do blog Temos que falar sobre isso:

Cada vez que comento que uma mãe está errada, que a crucifico e julgo, estou restringindo minha própria liberdade de ser e agir como acredito ser o melhor. (...) Lembre que aquela que escreveu é alguém diferente de você, não convive com as mesmas pessoas, não vive sua história, logo, pensa e sente de uma forma única e singular. ${ }^{13}$

Já outros textos analisados reforçam a necessidade de considerar as divisões identitárias entre as próprias mulheres, como as intersecções de raça, de classe e de orientação sexual, mas acreditam que a sororidade tem o potencial de superá-las

\footnotetext{
${ }^{12}$ https://www.youtube.com/watch?v=tmN8QHMfCSA. Acesso: 28 ago. 2020.

13 https://temosquefalarsobreisso.wordpress.com/2016/02/19/sobre-sororidade-liberdade-einterpretacao-de-texto/. Acesso: 28 ago. 2020.
}

Dossiê Crise, Feminismo e Comunicação - https://revistaecopos.eco.ufrj.br/ 
sem apagá-las, unindo-as por aquilo que elas têm em comum. Há a visão de que a sororidade pode emergir entre comunidades que reúnam sujeitos em torno de algo mais do que somente o gênero; por exemplo, entre mulheres negras - sentimento expresso no post "Empatia, lugar de falar e sororidade: elas não desistiram"14, do Blogueiras Negras, em que a autora expressa o acolhimento sentido ao ouvir as palavras de escritoras negras que definem para ela, tanto no conteúdo das mensagens quanto no ato de falar em um mundo que as oprime pela raça e pelo gênero, o sentido de sororidade.

0 verbete sororidade no dicionário on-line Significados ${ }^{15}$ traz, além da definição, uma explicação da sororidade seletiva, um uso nocivo do sentimento que excluiria determinados grupos femininos, como as transexuais, reforçando assimetrias entre mulheres que privilegiariam aquelas em posição de poder. 0 verbete ressalta a potência da sororidade, mas ressalta o risco de que o conceito possa ser usado para manter estruturas de dominação. Do mesmo modo, o texto publicado no portal jurídico Justificando, o primeiro de uma coluna intitulada "Sororidade em pauta", reforça a importância de ultrapassar essa sororidade seletiva.

E, ao combater naturalizações que historicamente justificam desigualdades e endossam discursos de sua própria subjugação, as mulheres começam a perceber, juntas, outras amarras que pretendem oprimir e calar, arraigadas de preceitos classistas, racistas, lesbofóbicos e transfóbicos. Não se trata assim, de um feminismo branco, burguês e cis (de mulheres cujo gênero equivale àquele designado em seu nascimento), mas, sim, da sororidade que abarca todas as mulheres possíveis.

Nesses discursos, a sororidade traria como potência uma irmandade que percebe a outra como a outra, sem a pretensão de diluir o self e a alteridade,

\footnotetext{
14 http://blogueirasnegras.org/2017/11/08/empatia-lugar-de-falar-e-sororidade-elas-naodesistiram/. Acesso: 28 ago. 2020.

${ }^{15}$ https://www.significados.com.br/sororidade/. Acesso: 28 ago. 2020.
}

Dossiê Crise, Feminismo e Comunicação - https://revistaecopos.eco.ufrj.br/

ISSN $2175-8689$ - v. 23, n. 3, 2020

DOI: 10.29146/eco-pos.v23i3.27601 
atualizando a união política feminina em torno de questões contemporâneas e atribuindo perspectivas de gênero à discussão em torno do conceito de empatia.

É necessário fazer a ressalva de que, na internet, circulam dúvidas de que esse projeto de irmandade feminina seria possível no contemporâneo, em que a diferença se estabelece como valor no contexto dos movimentos sociais orientados por políticas de identidade. As implicações éticas dessa reivindicação política em torno da sororidade são discutidas nos textos agrupados sob a categoria limites $d a$ sororidade, em que o sentimento é apontado como uma ferramenta nociva que invisibiliza (e assim mantém) opressões de raça, de classe e de faixa etária, conforme será analisado em futuros trabalhos.

\section{Sororidade: essência feminina ou prática feminista?}

Outro dissenso encontrado entre os textos é em relação à origem do sentimento de sororidade. Enquanto, para alguns discursos, ele seria uma atribuição natural das mulheres, para outros, ele representaria uma decisão ética a ser tomada e assumida como instrumento político, sendo uma experiência afetiva que emanaria da sociabilidade feminina e das práticas de ajuda mútua entre mulheres.

Em cinco textos, a sororidade aparece como parte de uma essência feminina e, em dois deles, como um sentimento inconsciente que emana do interior das mulheres: "A ideia de sororidade já está dentro das mulheres, mesmo que inconscientemente" ( $O$ Globo) e "Sororidade: um substantivo que habita no inconsciente feminino" (Projeto Estelar). Outros dois conteúdos atrelam o conceito de sororidade a temáticas ligadas ao campo semântico do esoterismo, reforçando uma relação entre a essência da feminilidade e o corpo:

A palavra sororidade não existe nos dicionários. Mas existe em um lugar sagrado chamado força interna feminina. Sóror quer dizer irmã. Sororidade é a capacidade que as mulheres possuem em se reconhecerem como irmãs. (...) Vamos aproveitar a energia da

Dossiê Crise, Feminismo e Comunicação - https://revistaecopos.eco.ufrj.br/

ISSN $2175-8689$ - v. 23, n. 3, 2020

DOI: 10.29146/eco-pos.v23i3.27601 
palavra sagrada Sororidade e rezar por todas as mulheres que precisam se curar no mundo (O Mundo de Gaya) ${ }^{16}$.

0 sagrado feminino age em rede, liga um útero ao outro, uma flor à outra, todas se dão as mãos, trocam seus formatos, sentem e cheiram as suas cores e caminham unidas curando a Terra e a si mesmas. (...) Não há um manual do que seja essa tal sororidade ou sagrado feminino. Para mim, é como digital e cheiro de corpo: cada uma acha a sua forma de ser esse estado do feminino. (...) Minha sororidade tem perfume de camomila, minha essência é de abraço e acolhimento, sou pisciana (Vertigem) ${ }^{17}$.

Esses discursos revelam que a popularização do conceito de sororidade significou sua apropriação por outros campos distintos do feminismo, de seus pressupostos, saberes e objetivos. É o que Foucault $(2009,2011)$ denomina como polivalência tática dos discursos: não há um enunciado intrinsecamente ligado ao poder e outro que seja, em si mesmo, a resistência a ele, e sim um complexo fluxo de apropriações desses discursos.

A sororidade, apesar de ter emergido em uma formação discursiva associada a um movimento político de resistência, pode ter múltiplas ressignificações que precisam ser analisadas em seus contextos. Nesses dois últimos casos, a sororidade reforça a ideia de que há uma essência da feminilidade, ligada a uma força que vem do corpo (especialmente ao útero) e à capacidade natural de expressar sensibilidade. Em quatro dos cinco textos, não há menção ao feminismo, e a sororidade aparece atravessada por outras formações discursivas, do campo do esoterismo, das religiões, da psicologia e de estratégias argumentativas apontadas frequentemente como patriarcais e machistas.

A ideia de essência feminina foi fortemente combatida pelo feminismo, especialmente pela segunda onda do movimento. Um de seus principais ícones, a filósofa francesa Simone de Beauvoir (1970), mostrou como a subjetividade feminina era construída no interior da cultura. Se a referência à sororidade como a expressão da força feminina e de uma união pelo útero, por um lado, ressignifica o

\footnotetext{
${ }^{16} \mathrm{https://omundodegaya.wordpress.com/2017/02/09/sororidade/.} \mathrm{Acesso:} 28$ ago. 2020.

17 http://www.revistavertigem.com/2016/04/07/um-perfume-para-a-sororidade/. Acesso: 28 ago. 2020.
}

Dossiê Crise, Feminismo e Comunicação - https://revistaecopos.eco.ufrj.br/ 
corpo feminino revertendo o discurso histórico da medicina que atribuiu a esse órgão a causa de fluxos emocionais instáveis e perigosos (Vieira, 2002), por outro lado, reafirma uma relação natural entre sentimentos, feminilidade e corpo, afastando esses conceitos de visões sociais e políticas. Tanto os sentimentos quanto as mulheres (não por acaso consideradas seres emocionais) aparecem, em discursos científicos e do senso comum, como entidades naturais, portanto caóticas e passíveis de regulação (Freire Filho, 2017; Lutz, 1990), visões que a ideia de essência feminina defendida por esses textos acaba por reforçar.

Os outros nove links da amostra não abordam a noção de essência feminina, aproximando a sororidade de uma resposta sentimental e política à uma sociedade patriarcal. A ideia de uma necessidade de falar da sororidade como um conceito que engendra uma prática de transformação da sociedade perpassa os discursos, estando presente em três dos títulos: "O que é sororidade e por que precisamos falar sobre" (Justificando); "O que quer dizer "sororidade" e por que você precisa dela" (Claudia) e "Mônica Martelli: precisamos falar sobre sororidade" (Cosmopolitan texto 2) ${ }^{18}$. Esses discursos midiáticos atuam em uma função pedagógica (Fischer, 2012). Essa defesa da sororidade como uma experiência válida e importante se apresenta, inclusive, como uma contrapedagogia que responde a valores e formas de sociabilidade ensinadas em uma cultura patriarcal, representados, principalmente, pela ideia de rivalidade. Como afirma a matéria de $O$ Globo, a sororidade é uma "uma espécie de antônimo da suposta rivalidade existente entre elas" e refere-se à misoginia como o contrário desse sentimento ("A misoginia - e a sororidade, seu antídoto"). Assim, a sororidade consistiria no instrumento para transformar os modelos de sociabilidade feminina que esses discursos consideram dominantes e problemáticos.

$\mathrm{Na}$ reportagem “Dicionários devem inserir palavras como 'sororidade' e 'feminicídio'”, do Correio Braziliense, apresenta-se uma construção histórica das relações entre mulheres até a emergência do vocábulo. Um paralelo com a

18 https://cosmopolitan.abril.com.br/estilo-de-vida/monica-martelli-precisamos-falar-sobresororidade/. Acesso: 28 ago. 2020.

Dossiê Crise, Feminismo e Comunicação - https://revistaecopos.eco.ufrj.br/

ISSN $2175-8689$ - v. 23, n. 3, 2020

DOI: 10.29146/eco-pos.v23i3.27601 
fraternidade é feito no texto de uma forma significativa: a troca do gênero do prefixo em latim marcaria uma experiência de significado diferente:

No caso de palavras como "sororidade", a questão não é apenas técnica ou formal. 0 sentimento de companheirismo entre mulheres tem um significado bastante diferente do que os homens sentem entre si. Depois de todo um passado histórico (e um presente) repressivo, a cumplicidade feminina tem uma carga afetiva própria, de resistência, com códigos e comportamentos diferenciados. ${ }^{19}$

Portanto, o sentimento de sororidade não representaria um mero espelhamento da fraternidade, mas carregaria em seus sentidos a construção histórica das relações entre mulheres dentro de uma sociedade dividida a partir de oposições generificadas entre público e privado (Perrot, 1998), articulando-se no contemporâneo a movimentos de resistência e novas produções da subjetividade feminina em negociações discursivas com o movimento feminista.

No conteúdo publicado pelo portal Justificando, a sororidade é definida como um sentimento que surge a partir da vivência prática das mulheres, tornando-se possível somente após uma tomada de consciência sobre as tentativas do patriarcado de estabelecer a desunião entre elas. Ela seria a resposta a um movimento de naturalização da rivalidade feminina, produzido no interior da cultura. Um aspecto chave para o despertar da sororidade seria a sociabilidade entre mulheres:

Assim, a sororidade, enquanto termo e enquanto sentimento, surge e se fortalece da necessidade das mulheres de compartilharem experiências subjetivas, a partir de relações positivas e saudáveis umas com as outras, formando e fomentando alianças pessoais, sociais e políticas, empoderando-se e criando elos importantes para

${ }^{19} \mathrm{http}: / /$ www.correiobraziliense.com.br/app/noticia/diversao-earte/2016/05/17/interna diversao arte,532238/dicionarios-devem-inserir-palavras-comosororidade-e-feminicidio.shtml. Acesso: 28 ago. 2020.

Dossiê Crise, Feminismo e Comunicação - https://revistaecopos.eco.ufrj.br/

ISSN $2175-8689$ - v. 23, n. 3, 2020

DOI: 10.29146/eco-pos.v23i3.27601 
combater e eliminar as diversas formas de opressão perpetuadas ao longo dos séculos pelo patriarcado. ${ }^{20}$

Para a reportagem de Claudia $^{21}$, a sororidade, aliada ao sentimento de indignação, foi capaz de levar milhares de mulheres a manifestarem nas ruas contra um caso de estupro coletivo ocorrido em 2016. Nesses e em outros discursos, aparece a força do conceito como ferramenta de mudança feminista, capaz de impulsionar atos coletivos que visam transformar estruturas sociais. No texto publicado pelo HuffPost, a sororidade é definida inclusive como a segunda (e mais importante) lição do feminismo. Ela promoveria avanços em relação a um primeiro período, em que as vertentes contemporâneas do movimento teriam promovido, principalmente, a ideia de autoestima e de empoderamento individual.

No ano passado [2015], aprendemos que chega de fiu fiu; que, independente do tamanho da saia, a culpa nunca é nossa; meu corpo, minhas regras; piada machista não tem graça; e, finalmente, reclamamos por liberdade individual e sexual, não por ser um capricho, mas sim um direito. (...) Agora que você já aprendeu a amar seu corpo e a não aceitar ser tratada como um objeto, está na hora de fazer isso com a coleguinha do lado. (...) Não adianta amar seu corpo e transar com quem você quiser se você chama a outra de gorda ou puta. 22

A sororidade seria o sentimento capaz de transformar o feminismo em uma ação coletiva. Sua ausência significaria praticar uma política limitada, que não seria capaz de realizar transformações mais amplas e permaneceria circunscrita ao âmbito psicológico e individual. Em minha análise sobre o estereótipo da mulher poderosa em revistas semanais de informação brasileiras entre 2010 e 2014, os resultados apontaram para a predominância de uma concepção de feminismo centrada na ideia de empoderamento individual. Em um viés psicologizante, a

20 http://justificando.cartacapital.com.br/2016/06/02/o-que-e-sororidade-e-por-que-precisamosfalar-sobre/. Acesso: 28 ago. 2020.

21 https://claudia.abril.com.br/noticias/o-que-quer-dizer-sororidade-e-por-que-voce-precisadela/. Acesso: 28 ago. 2020.

22 http://www.huffpostbrasil.com/marianna-victor/sororidade-e-palavra-que-traz-a-licao-maisimportante-do-femin a_21695261/. Acesso: 28 ago. 2020.

Dossiê Crise, Feminismo e Comunicação - https://revistaecopos.eco.ufrj.br/

ISSN 2175-8689 - v. 23, n. 3, 2020

DOI: 10.29146/eco-pos.v23i3.27601 
mulher deveria buscar em si mesma - e não nas desigualdades estruturais - as causas de um possível fracasso. Esse feminismo se afastaria de lutas políticas coletivas para se tornar um movimento individual na busca do sucesso, mostrandose interessante para o ethos neoliberal. Nesse contexto, a união entre mulheres não seria uma prioridade (Leal, 2015).

Portanto, esse tipo de feminismo representado em veículos da mídia tradicional parecia se encaminhar para o caminho da retórica neoliberal, do consumo e do sucesso, corroborando o que McRobbie (2006) e Gill (2007) identificavam como tendência predominante do chamado pós-feminismo. Contudo, no mesmo contexto foi possível observar a proliferação de blogs, de grupos e de páginas no Facebook em que as mulheres se chamavam de "manas" e se uniam em torno de uma luta política feminista, denunciando as opressões que sofriam e reforçando a necessidade de um movimento coletivo. A sororidade emerge, assim, como um conceito possível para visões políticas e coletivas do movimento. Podemos considerar o ethos neoliberal tanto como condição de possibilidade para a própria emergência do conceito como resistência quanto para a reorganização dos fluxos de poder que permitem que ele seja também apropriado por discursos voltados ao empoderamento individual, a campanhas de marketing e promoção do consumo e a um afastamento do feminismo nos discursos de manutenção da ideia de essência feminina.

É interessante observar que a internet não aparece apenas como plataforma de veiculação desses discursos, mas relacionada à própria ideia de ação política coletiva. Aqui, aparece a ideia de que a popularização dos sites de redes sociais e das tecnologias de informação e comunicação estão atreladas à emergência de uma quarta onda feminista (Queiroz, 2016, Hollanda, 2019). No vídeo de Capricho, a internet já é apresentada a priori como campo primordial de prática da sororidade, na própria fala da repórter em sua abertura: "E hoje nesse dia especial a gente vai falar sobre sororidade, como a gente pode ajudar outras meninas na internet". Ela afirma que, especialmente para as adolescentes, que enfrentam a não permissão dos pais para frequentar determinados locais e a falta de recursos financeiros próprios, a internet emerge como um lugar primordial em que elas podem fazer a diferença.

Dossiê Crise, Feminismo e Comunicação - https://revistaecopos.eco.ufrj.br/

ISSN 2175-8689 - v. 23, n. 3, 2020

DOI: 10.29146/eco-pos.v23i3.27601 
No total, oito dos textos da amostra celebram as potencialidades da internet, mencionando campanhas feministas baseadas em hashtags como \#VamosJuntas?, \#MeuPrimeiroAssédio e \#ChegadeFiuFiu e \#MeToo como exemplos de práticas de sororidade ou afirmando o potencial da rede para despertar o sentimento de união feminina ou para exercitar o olhar empático para as outras mulheres. A análise da categoria sororidade na prática em futuros trabalhos poderá auxiliar a mensurar o papel da internet na prática feminista nos discursos sobre esse sentimento, contribuindo para pensar a mídia como mediação sociocultural na construção de moralidades, subjetividades e formas de ação política no contemporâneo.

\section{Considerações finais}

A dispersão discursiva realizada neste artigo revela que as respostas para a pergunta “o que é sororidade?" são múltiplas em significados, apropriações e práticas. Os enunciados que compõem a amostra analisada, agrupados sob a categoria definições de sororidade, divergem sobre as origens do sentimento, ora considerando-o como parte de uma essência ou manifestação do inconsciente feminino, ora defendendo que ele seja resultado de uma postura ético-política desenvolvida a partir da sociabilidade entre mulheres em um mundo patriarcal.

A multiplicidade de respostas à pergunta "o que é sororidade" ressalta que, se o conceito se torna pensável dentro da formação discursiva do feminismo, sua circulação ultrapassa os limites desse campo. Os discursos que a definem como expressão de uma essência feminina parecem ir na contramão da própria luta feminista, reforçando visões tradicionais da feminilidade. Assim, o termo não pertence exclusivamente ao feminismo; e, sim, demonstra que a circulação midiática do movimento está aberta a diversas apropriações. Há uma polivalência tática nesses enunciados, que podem ser potentes e, ao mesmo tempo, contraditórios.

Por outro lado, aparece como continuidade entre os textos o uso do campo semântico emocional para definir a sororidade. Ela é um sentimento em si mesma e mobiliza outros, tanto por oposição - ódio, ciúme, egoísmo - quanto por semelhança - amizade, solidariedade, amor, indignação e, especialmente, simpatia e empatia. Analisar a genealogia dos dois últimos oferece pistas para compreender a 
emergência de um sentimento moral feminino no contexto contemporâneo, marcado pelas lutas identitárias, pela política da diferença e também por um ethos neoliberal que engendra poderes e resistências.

Há, portanto, um nexo entre sentimentos, moralidade, política e mídia em torno do conceito de sororidade. A internet aparece tanto como uma arena em que esses discursos são produzidos e veiculados quanto como uma ferramenta com potencial de apropriação pelas mulheres. Explorar que tipos de iniciativas são classificadas como práticas de sororidade, que produtos midiáticos são considerados como suas representações e quais são os limites enxergados pelas ativistas nos usos do conceito permitirá aprofundar e complexificar a análise de discursos sobre a sororidade, para que seja possível compreender, além do que ela é, que identidades, noções de moralidade e práticas comunicacionais ela produz.

\section{Referências bibliográficas}

AHMED, Sara. Living a feminist life. Durham: Duke University Press, 2017.

ANJOS, Júlia Cavalcanti Versiani dos. Megeras (in)domadas: discurso de ódio antifeminista nas redes sociais. Dissertação (Mestrado). Universidade Federal do Rio de Janeiro, Programa de Pós-Graduação em Comunicação. Rio de Janeiro, 2019.

BEAUVOIR, Simone de. O segundo sexo - volume 1: fatos e mitos. São Paulo: Difusão europeia do livro, 1970.

BOGADO, Maria. Rua. In: HOLLANDA, Heloisa Buarque de. Explosão feminista: arte cultura, política e universidade. São Paulo: Companhia das Letras, 2019.

BUITONI, Dulcília Helena Schroeder. Imprensa feminina. Rio de Janeiro: Ática, 1986.

COPLAN, Amy; GOLDIE, Peter. Empathy: philosophical and psychological perspectives. Oxford: Oxford University Press, 2011.

COSTA, Suely Gomes. Onda, rizoma e "sororidade" como metáforas: representações de mulheres e dos feminismos (Paris, Rio de Janeiro: anos 70/80 do século XX). INTERthesis, v. 6, n. 2, p. 01-29, 2009.

DEBES, Remy. From Einfühlung to empathy: sympathy in early Phenomenology and Psychology. In: SCHLIESSER, Eric (Ed.). Sympathy: a history. Oxford: Oxford University Press, 2015, p. 286-322.

\section{Dossiê Crise, Feminismo e Comunicação - https://revistaecopos.eco.ufrj.br/}

ISSN $2175-8689$ - v. 23, n. 3, 2020

DOI: 10.29146/eco-pos.v23i3.27601 
DUARTE, Constância Lima. Imprensa feminina e feminista no Brasil: século XIX - dicionário ilustrado. Belo Horizonte: Autêntica, 2016.

FISCHER, Rosa Maria Bueno. Trabalhar com Foucault: arqueologia de uma paixão. Belo Horizonte: Autêntica, 2012.

FOUCAULT, Michel. A arqueologia do saber. Rio de Janeiro: Forense Universitária, 2009.

História da sexualidade I: a vontade de saber. São Paulo: Paz e Terra, 2011.

FRAISSE, Geneviève. Préface. In: KOLLY, Bérengère; “Et de nos soeurs séparées...”: lectures de la sororité. Fontenay le Comte: Lussaud, 2012.

FREIRE FILHO, João. Correntes da felicidade: emoções, gênero e poder. Matrizes, v. 11, n. 1, 2017, p. 61-81.

FREVERT, Ute. Emotions in history: lost and found. Central European University Press: Budapeste/Nova Iorque, 2011.

GILL, Rosalind. Análise do discurso. In: BAUER, Martin W.; GASKELL, George. Pesquisa qualitativa com texto, imagem e som: um manual prático. Petrópolis: Vozes, 2002, p. 244270.

Gender and the media. Nova Hampshire: Polity, 2007.

GREY, Breda. Empathy, emotion and feminist solidarities. In: RUBERG, Willemijn; STEENBERGH, Kristine. Sexed sentiments: interdisciplinary perspectives on gender and emotion. Nova Iorque: 2011, 207-232.

HOLLANDA, Heloisa Buarque de. Explosão feminista: arte, cultura, política e universidade. São Paulo: Companhia das Letras, 2019.

HOUAISS, Antônio; VILLAR, Mauro. Dicionário Houaiss eletrônico da língua portuguesa. Rio de Janeiro: Objetiva, 2009. CD-ROM.

HUME, David. Tratado da natureza humana. São Paulo: Unesp, 2009.

IRVINE, Janice. M. Transient feelings: sex panics and the politics of emotions. GLQ: A Journal of Lesbian and Gay Studies, v. 14, n. 1, 2007, p. 1-40.

LEAL, Tatiane. A invenção da sororidade: sentimentos morais, feminismo e mídia. Tese (Doutorado). Universidade Federal do Rio de Janeiro, Programa de Pós-Graduação em Comunicação. Rio de Janeiro, 2019.

LEAL, Tatiane. A mulher poderosa: construções da vida bem-sucedida feminina no jornalismo brasileiro. Dissertação (Mestrado). Universidade Federal do Rio de Janeiro, Programa de Pós-Graduação em Comunicação. Rio de Janeiro, 2019.

Dossiê Crise, Feminismo e Comunicação - https://revistaecopos.eco.ufrj.br/

ISSN $2175-8689$ - v. 23, n. 3, 2020

DOI: 10.29146/eco-pos.v23i3.27601 
LUTZ, Catherine. Engendered emotion: gender, power and the rhetoric of emotional control in American discourse. In: LUTZ, Catherine A.; ABU-LUGHOD, Lila (Eds.). Language and the politics of emotion. Nova Iorque: Cambridge University Press, 1990, p. 69-91.

MCROBBIE, Angela. Pós-feminismo e cultura popular: Bridget Jones e o novo regime de gênero. Cartografias Estudos Culturais e Comunicação, Porto Alegre, 2006, p. 1-10.

PERROT, Michelle. Mulheres públicas. São Paulo: Unesp, 1998.

QUEIROZ, Nana (Ed.). Você já é feminista! Abra este livro e descubra o porquê. São Paulo: Pólen, 2016.

RIBEIRO, Djamila. O que é lugar de fala? Belo Horizonte: Letramento, 2017.

SMITH, Adam. Teoria dos sentimentos morais. São Paulo: Martins Fontes, 2015a.

SMITH, Tiffany Watt. The book of human emotions: from ambiguphobia to umpty - 154 words from around the world for how we feel. Nova Iorque: Little, Brown and Company, 2015b.

TAYLOR, Charles. A ética da autenticidade. São Paulo: Realizações, 2011.

As fontes do self: a construção da identidade moderna. São Paulo: Loyola, 2013.

VIEIRA, Elizabeth Meloni. A medicalização do corpo feminino. Rio de Janeiro: Fiocruz, 2002.

ZAYTOUN, Kelli; EZEKIEL, Judith. Sisterhood in movement: feminist solidarity in France and the United States. A Journal of Women Studies, v. 37, n. 1, p. 195-214, 2016. 